\title{
Modos diversos de atingir a Índia: gêneros literários e descontinuidade
}

\section{Different ways of achieving India: literary genres and descontinuity}

Francine Weiss Ricieri

Universidade Federal de São Paulo (UNIFESP), São Paulo, São Paulo, Brasil francine.idt@terra.com.br

Resumo: Publicado em 2010, Uma viagem à Índia: melancolia contemporânea (um itinerário), de Gonçalo M. Tavares, é um poema narrativo, com 10 seções denominadas "cantos", que se organiza, entre outros aspectos, por analogias formais com Os Lusíadas, para mencionar apenas um dos livros com que dialoga. Além de cada canto da obra contemporânea conter o exato número de estâncias presentes no poema de Luís de Camões, discernem-se outras aproximações, em diversos níveis, o que parece permitir supor que o modo de produção de sentidos do poema mais recente possa ser entendido como relacional. O objetivo desta exposição é discutir o modo como se abre o poema contemporâneo, em cujo subtítulo delineia-se um itinerário, ancorado no termo "melancolia". Esboçam-se, ainda, alguns movimentos de análise da poética que acompanharia o projeto ficcional do livro, bem como das peculiaridades e das indefinições de gênero literário de Uma viagem à Índia (que dialoga com a tradição épica, com a tradição do poema narrativo dos séculos XIX e XX, bem como com produções romanescas como o Ulisses, de James Joyce). Como esse livro especificamente pode contribuir com redimensionamentos de tais tradições é questão não alheia à discussão.

Palavras-chave: Gonçalo M. Tavares; poema narrativo; tradição épica; Camões 
Abstract: Gonçalo M. Tavares has published, in 2010, a book entitled Uma viagem à Índia: melancolia contemporânea (um itinerário). This narrative poem is organized in 10 sections called "cantos", showing a great amount of evidences of formal parallelism with Os Lusíadas (Camões'epic), among other dialogues with tradition (James Joyce's Ulysses and also the greek ancestor and formal model, Odyssey). The proposal of this paper is to discuss how and in what measure those parallelisms may suggest relacional reading strategies. It should be considered, in addition, the subtitle of the book: "melancolia contemporânea (um itinerário)". In addition, it will be added some appointments about a certain poetic that organizes the contemporary book, as well as some short reflexions about gender indefinitions in the same book (that evokes elements taken from epic tradition, narrative poem tradition as well as Romanesque tradition). How could this book specifically contribute to reconstruct or not such traditions is not a question strange to this proposal.

Keywords: Gonçalo M. Tavares; Narrative poem; Epic tradition; Camões

Recebido em 14 de setembro de 2014. Aprovado em 15 de novembro de 2014.

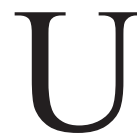

Tma primeira abordagem, em se tratando de pensar o livro Uma viagem à Índia, ${ }^{1}$ de Gonçalo M. Tavares, encontrase sugerida e realizada na recensão crítica publicada em maio de 2011, por Vasco Graça Moura, na revista Colóquio/Letras. ${ }^{2}$ Ali, em meio a uma inicial problematização que remete ao incontornável problema do gênero literário a que se pudesse filiar o volume, indicam-se "matrizes mais ou menos remotas da sua trama que, em parte, mas só em parte", ${ }^{3}$ a explicariam. O crítico reporta-se a três matrizes, em específico, duas das quais estariam certificadas por evidências diretamente coletadas nas páginas do volume em questão. A primeira delas apareceria já na denominação dada ao protagonista da viagem em causa, Bloom, remissão direta às páginas de Joyce. Esse Bloom, não obstante, é português e movimenta-se no corpo de um texto cuja apresentação evidencia, a cada momento, a relação com a segunda e mais óbvia matriz, Os Lusíadas,

\footnotetext{
1 TAVARES, 2010.

${ }^{2}$ MOURA, 2011, p. 271-274.

${ }^{3}$ MOURA, 2011, p. 272.
} 
de Camões. Mais óbvia, já que excessiva, redundante, sem economia: o livro de Tavares, como se sabe e muito se comenta, organiza-se em dez partes, cada uma das quais estruturalmente espelhável em relação ao canto equivalente da epopeia camoniana. Para Vasco Graça Moura, o poema de Camões forneceria, de resto, "uma bússola e uma cartografia de leitura", mesmo quando (ou talvez principalmente quando) a exaustiva convocação das páginas quinhentistas viesse marcada pela dissonância e pela distorção. A terceira matriz, a Odisseia, estaria entranhada à própria fatura das duas outras, sendo, nesse sentido, para o crítico, "mais importante porque fundacional". Sinteticamente, Moura aponta a seguinte configuração: "Bloom é pois um novo Ulisses que parte da Ulisseia, afinal a cidade que fundou e a que há-de regressar".

Tomando como pressuposto da leitura que ora se tenta empreender as complexas relações estabelecidas pelo livro de Tavares com as matrizes indicadas por Moura, uma segunda abordagem nos levaria a examinar um pouco mais detidamente o título do livro em análise, que, em sua página de rosto, revela-se duplicado em título e subtítulo: Uma viagem à Índia: melancolia contemporânea (um itinerário). Nesse sentido, "melancolia" seria, talvez, o primeiro elemento demandando algumas considerações, o que será feito a partir daquele pressuposto relacional. Fernando Pinto do Amaral, no Dicionário de Luís de Camões, ${ }^{4}$ organizado por Vítor Aguiar e Silva, historia as transformações do conceito de melancolia desde a Antiguidade, discriminando grandes polos de significação a ele associáveis. Inserindo a obra de Luís de Camões no quadro cultural renascentista e também aproximando-a da crise do ideal humanista situada no século XVI, Fernando Pinto do Amaral constata uma agudização da melancolia em poetas ou artistas do período, o que estaria relacionado a "uma consciência mais sombria da fragilidade humana num mundo repleto de fraturas e incertezas". Camões constituiria, de resto, um dos paradigmas centrais da melancolia quinhentista,

[...] já que na segunda metade do século XVI a melancolia surge como consequência de uma visão angustiada pelo absurdo e pelo "desconcerto" de um mundo no qual por vezes nem os próprios valores religiosos se mostram suficientes para sustentar uma arquitetura espiritual equilibrada e coerente. ${ }^{5}$

\footnotetext{
${ }^{4}$ AMARAL, 2011.

${ }^{5}$ AMARAL, 2011, p. 583.
} 
Para ir diretamente a uma das fontes do raciocínio de Amaral, talvez seja o caso de recuperar alguns elementos desenvolvidos por Vítor Aguiar e Silva em seu ensaio "As canções da melancolia: aspectos do maneirismo de Camões". ${ }^{6}$ Retomando o pensamento de Aristóteles, Dante, Petrarca, o estudioso chega ao tratado de Marsílio Ficino, De Amore, que profunda influência teria exercido em meios cultos do Renascimento. Destaco:

$\mathrm{Na}$ raiz da melancolia ficiniana encontra-se o sentimento de uma perda originária: a perda da unidade originária, como é reiteradamente afirmado no De Amore [...]. Esta perda originária é um afastamento do Pai, da plenitude do Uno. Saturno é o deus do tempo e, por conseguinte, da diferenciação e da separação, mas é também o deus do desejo da nostalgia, isto é, do desejo de regresso à unidade originária. E por isso a melancolia dos homens invulgares, colocada sob o signo de Saturno, é um estado de espírito que configura a nobreza e a dignidade por excelência do homem: é a consciência dos limites da condição humana, é a memória da plenitude perdida e o reconhecimento da caducidade e da fragmentação presentes, mas é também a impulsão, a atitude dinâmica, a potentio para recuperar o bem originário, para retornar ao Pai, num movimento de epistrophē que é fundamental no neoplatonismo renascentista. A melancolia ficiniana, em suma, inscreve-se numa antropologia optimista e heroica, pois que a perda não é pensada como irrevogável, nem o homem se afunda numa tristeza lutuosa ou se excrucia numa culpabilidade desesperada. ${ }^{7}$

Valeria assinalar que o referido ideal antropológico renascentista entraria em questão ainda no primeiro quartel do século XVI, sendo a tela Melencolia I, de Gustave Dürer, datada de 1514, já marcada por uma simbolização da paralisia da vontade diante da nulidade dos empreendimentos humanos. Seguindo ainda a análise de Aguiar e Silva, mesmo sem que se possa registrar a ocorrência da palavra melancolia ou de suas variantes, em especial a lírica camoniana atualizaria equivalentes que encenariam aquela perda originária. Ainda segundo o mesmo crítico,

${ }^{6}$ SILVA, 1994, p. 209-228.

${ }^{7}$ AMARAL, 2011, p. 213. 
a tópica da "errância", da "peregrinação sem descanso", um dos azares impostos ao homem pela Fortuna, apareceria, nesta lírica e em algumas ocorrências específicas em Os Lusíadas, contraposta pelo poeta "ao sossego e à segurança do pátrio ninho amado", ninho que remeteria por sua vez à imagem da terra do pai. As análises contidas no ensaio a que me reporto exploram de um modo que não poderei reproduzir aqui o que seriam as diferenças recorrentes no pensamento neoplatônico entre as figuras paterna e materna. Limito-me a destacar que a terra natal apareceria como terra do pai, enquanto a expressão "materno ninho", presente em algumas das elegias analisadas no texto, combinada ao adjetivo escuro, atualizaria um sentido disfórico, já que o retorno ao seio materno simbolizaria a recondução ou o enclausuramento em uma sepultura. Como contraponto, o ninho paterno ou pátrio configuraria "um espaço que consubstancia o amor, que simboliza a identidade, a permanência e a unidade do homem". ${ }^{8}$ Ou seja, a "errância atormentada pelo espaço" seria acompanhada por uma "fixação obsessiva no tempo passado", em clara tentativa de recuperação da cousa amada. Em contrapartida, a separação do pai, ou da terra do pai, instauraria a perda originária, constituiria o melancólico.

O livro de Gonçalo M. Tavares reporta-se a uma melancolia a que se acresce o adjetivo "contemporânea" e um aposto que a assimila a um itinerário. Nesse sentido, e em se tratando, como se disse, de livro que se constrói incorporando a relação com outros livros, parece ser o caso de examinar melhor essa outra errância, essa viagem a alguma Índia, certamente não àquela a que teria tentado chegar o "bicho da terra vil e tão pequeno" camoniano. Percurso melancólico para o qual se convoca uma situação histórica que se aparta de um sentido épico tout court. Assumindo, enfim, uma perspectiva que não é o objetivo desse texto desenvolver em todas as suas implicações, talvez seja o caso de assinalar algo de fundamente melancólico também nessa atualização fantasmática de uma empresa épica que já não se pode formular senão como simulacro.

Tomemos, então, o modo como se abre o poema que nos é contemporâneo:

${ }^{8}$ SILVA, 1994, p. 223. 
Não falaremos do rochedo sagrado onde a cidade de Jerusalém foi construída, nem da pedra mais respeitada da Antiga Grécia situada em Delfos, no monte Parnaso, esse Omphalus - umbigo do mundo para onde deves dirigir o olhar, por vezes os passos, sempre o pensamento.

2

Não falaremos do Três Vezes Hermes nem do modo como em ouro se transforma o que não tem valor - apenas devido à paciência, à crença $\mathrm{e}$ às falsas narrativas.

Falaremos de Bloom e de sua viagem à Índia. Um homem que partiu de Lisboa.

3

Não falaremos de heróis que se perderam em labirintos nem da demanda do Santo Graal. (Não se trata aqui de encontrar a imortalidade mas de dar um certo valor ao que é mortal.) Não se abrirá uma cova para encontrar o centro do mundo, nem se procurará em grutas nem em caminhos da floresta as visões que os Índios idolatravam.

4

Não se trata aqui de fazer um jejum no alto da montanha sagrada para que a fraqueza e os ares elevados possibilitem tremores e doenças benignas. Trata-se simplesmente de constatar como a razão ainda permite algumas viagens longas.

Falaremos de Bloom. 
As dez primeiras estrofes de Uma viagem à Índia apresentam grande proximidade formal entre si. Dizendo de modo direto, parecem se construir como um longo exercício de preterição. Já nos Elementos de retórica literária, de Heinrich Lausberg, a preterição aparece como figurae per detractionem, constituindo uma "referência à situação do discurso" em que se anuncia expressamente "a intenção de deixar de lado o tratamento exaustivo de um objeto referido ou de vários [...] objetos referidos no discurso". ${ }^{9}$ Não deixa de ser curioso que, cuidando de fornecer exemplos de preterição, Lausberg recorra a esta estância de Os Lusíadas:

\author{
Deixo, Deuses, atrás a fama antiga \\ Que coa gente de Rômulo alcançaram, \\ Quando com Viriato, na inimiga \\ Guerra Romana, tanto se afamaram. \\ Também deixo a memória que os obriga \\ A grande nome, $[\ldots]$
}

Estamos no Canto Primeiro, estância 26. Em Camões, como é sabido, as três estâncias que abrem o poema anunciam os feitos que estabelecerão a matéria heroica e, ainda que a terceira estância utilize quatro versos em referência à fama que se deve calar diante do que se anuncia, trata-se de três estrofes cuja economia não deixa dúvidas quanto ao tema em proposição. Camonistas como Isabel Almeida assinalam que, nos primeiros movimentos de Os Lusíadas, Camões dedica-se a "definir o estatuto, o rumo, a dignidade do poema que ali começa" 10 indicando suas relações, entre outros, com Orlando Innamorato e Orlando Furioso, que integrariam seu horizonte, contribuindo com a constituição de sentidos realizada pelo poema heroico. Empenhando-se em uma "demarcação de território", o poeta selecionaria modelos, posicionando-se, também, quanto à adoção ou ao desafio de códigos então considerados, além de estabelecer balizas para seu recurso à prática intertextual. Assim, Camões teria aprendido com Ariosto a "expor, na malha narrativa, uma figura de poeta, em proporções que infringem a norma da epopeia greco-latina", em alguns casos causando escândalo aos primeiros comentadores do poema.

Cleonice Berardinelli ${ }^{11}$ escreveu sobre essa voz do Poeta que de algum modo, como em Ariosto, emoldura o discurso dos narradores

\footnotetext{
${ }^{9}$ LAUSBERG, 1965, p. 242.

${ }^{10}$ ALMEIDA, 2008, p. 94.

${ }^{11}$ BERARDINELLI, 2000, p. 31-55.
} 
propriamente ditos do poema. Ao Poeta caberiam cerca de $8 \%$ de tudo o que se enuncia no poema, distribuindo-se sua participação em excursos (reflexões, exortações, queixas) entre os quais se incluiriam as partes iniciais do poema (Proposição, Invocação e a Dedicatória), bem como a exortação final a D. Sebastião, além dos inícios e fechos de cada Canto e dos diferentes momentos em que as Musas voltam a ser invocadas, entre comentários diversos. De todo modo, Isabel Almeida salienta os moldes quinhentistas de produção e consumo de poesia (destaquem-se as relações de mecenatismo), bem como seu enquadramento retórico, como discurso epidíctico, destinado, portanto, a louvar ou a reprovar. Ou seja, se os excursos do Poeta podem causar estranhamento a certa tradição, tanto Proposição quanto Dedicatória do poema não realizariam inovação em relação à mesma tradição: "nelas, como na Dedicatória que acrescentou, o Poeta é altamente laudatório e está penetrado da euforia do canto". ${ }^{12}$

As preterições com que se abre Uma viagem à Índia, nesse sentido, não podem ser assimiladas aos quatro versos que, na estância 3 de Os Lusíadas pedem que se calem as grandes navegações do sábio Grego e do Troiano, ou a fama das vitórias de Alexandre e de Trajano - silêncio com que se prepara o canto do ilustre. De antemão, e sem ter muito como fugir ao jogo de palavras, as preterições de Gonçalo não podem ser assimiladas às de Camões porque o poema de Gonçalo se abre sem proposição. Como se viu anteriormente, predominam até a nona estrofe os enunciados que se reportam ao que não se vai falar. É preciso chegar à décima estrofe para que se tenha uma enunciação mais claramente propositiva:

10

Falaremos da hostilidade que Bloom,

o nosso herói,

revelou em relação ao passado,

levantando-se e partindo de Lisboa

numa viagem à Índia, em que procurou sabedoria

e esquecimento.

E falaremos do modo como na viagem

levou um segredo e o trouxe, depois, quase intacto.

${ }^{12}$ BERARDINELLI, 2000, p. 43. 
Somados os setenta e dois versos que compõem as nove estrofes anteriores, apenas 14 têm alguma relação com a pretensa matéria do poema, ou com seu herói:

Falaremos de Bloom

e de sua viagem à Índia.

Um homem que partiu de Lisboa.

4

$[\ldots]$

Trata-se simplesmente de constatar como a razão ainda permite algumas viagens longas. Falaremos de Bloom.

6.

$[\ldots]$

Falaremos de um homem, Bloom, e da sua viagem ao início do século XXI.

7

$[\ldots]$

Falaremos de Bloom e da sua viagem De Lisboa à Índia.

8

$[\ldots]$

Falaremos de Bloom. E da sua viagem à Índia.

9

Falaremos de uma viagem à Índia.

E do seu herói, Bloom. 
Lausberg sublinhava ser a preterição um recurso por meio do qual a "situação do discurso" é referida. Não tenho dúvidas de que o livro em questão explícita ou implicitamente joga sistematicamente com a encenação de suas condições de produção acionando, entre outros fatores, intertextos diversos que favorecem essa encenação. Em toda sua extensão, aliás, aciona a cada momento recursos os mais diversos para colocar e manter em situação as condições de produção de sua discursividade. Um outro efeito, contudo, parece mais pertinente ao raciocínio que por ora venho tentando empreender: uma economia textual tão claramente empenhada em preterir antes mesmo de propor o que quer que seja parece gerar uma curiosa presentificação do que se busca eventualmente negar. Ocorre que a insistência em preterir rochedos sagrados, cidades históricas, pedras míticas, o deus da escrita e da sabedoria (Hermes Trimegisto, ou Toth), heróis mitológicos ou demandas cristãs, a insistente preterição, enfim, parece gerar um efeito de algum modo paradoxal. O que me levaria a passar de uma hipótese inicial que leria essas primeiras estrofes em termos de preterição a uma segunda tentativa, em que se pudesse pensálas talvez por duas outras perspectivas, que seriam respectivamente o conceito freudiano de denegação e aquela delimitação prévia constante do título do livro de um itinerário de possibilidades para a matéria em narração: o itinerário de uma certa melancolia, dita contemporânea.

No primeiro caso, sumariamente e sem me reportar aos intrincados problemas de tradução, recordaria, seguindo teóricos da psicanálise, que, em um texto de 1925, "A negativa", Freud descreve a denegação como "uma maneira de repelir, através de projeção, a ideia que acaba de aflorar em sua mente". ${ }^{13} \mathrm{O}$ sujeito oscilaria, portanto, entre a recusa e o reconhecimento, uma vez que faria vir à tona, projetando em forma discursiva, algum conteúdo reprimido que, assim, aparece sendo negado. Cito Freud: "A negativa constitui um modo de tomar conhecimento do que está reprimido (recalcado); com efeito, já é uma suspensão da repressão (do recalque), embora, não, naturalmente, uma aceitação do que está reprimido." Recorrendo a um comentarista, Oswaldo França Neto, seria possível acrescentar:

A dupla negação/afirmação está presente em Freud desde o início de seus trabalhos, que colocaram, no centro das discussões, as diferentes formas de defesa de que o aparelho

${ }^{13}$ FRANÇA NETO, 2006, p. 153. 
psíquico lança mão face ao que deve ser negado, escondido, rechaçado. No inconsciente não existe a palavra "não" (Freud, 1925/1976: 300). Lá é o império do "sim”, onde tudo é permitido, independentemente de responder ou não à lógica da razão ou às leis morais. Em oposição a ele teríamos a consciência, lugar por excelência do "não", onde as afirmações do consciente poderiam manifestar-se devidamente camufladas, ou então explicitamente sob a forma de uma negação: "Agora o senhor vai pensar que eu quero [...], mas realmente não tenho essa intenção.” (ibd: 295). Ou seja, o sujeito do desejo somente pode se fazer presente na consciência ao inventar, por meio de uma negativa, um compromisso acerca daquilo que recusa em si mesmo. ${ }^{14}$

Um compromisso acerca do que se recusa implica que no âmbito do mecanismo de denegação ocorreria uma aceitação, digamos, intelectual do conteúdo que se denega, não acompanhada contudo de sua aceitação afetiva. Aceita e declarada a existência de um dado conteúdo, o sujeito precisa ainda declarar-se dele distanciado. Considerando que o mecanismo descrito por Freud e aqui brevemente sumariado possa auxiliar a entender o modo como se abre Uma viagem à Índia, seria o caso talvez de sublinhar a diferença entre aquilo que, em cada um dos casos, nos versos de abertura se enuncia. Camões, em sua Proposição, engaja a voz poética, engrandece o feito, louva o herói, como é da convenção, do gênero, da retórica implicada. Denegando, mais do que preterindo, a outra viagem à Índia expõe como primeiro dado de que se constrói o texto nove estrofes em que se atrasam ou minimizam os sucessos do pretenso herói, pondo em primeiro plano um sucessivo arrolamento de valores, símbolos, ídolos e ideais mortos, tornados obsoletos e que aparentemente se pretende silenciar, exaustivamente referindo. Não é possível ao poeta que nos é contemporâneo, sob qualquer pretexto, engajar-se afetivamente nessa longa enumeração de valores e abstrações que, no entanto, impõe-se ao exame racional. Oscilação entre reconhecimento e recusa, a quarta estrofe presentifica melhor talvez que as demais os dois termos a que me refiro:

${ }^{14}$ FRANÇA NETO, 2006, p. 153-154. 
4

Não se trata aqui de fazer um jejum

no alto da montanha sagrada

para que a fraqueza e os ares elevados

possibilitem tremores e doenças benignas.

Trata-se simplesmente de constatar

como a razão ainda permite

algumas viagens longas.

Falaremos de Bloom.

Uma viagem longa, portanto, este itinerário em escrita, para a qual importa a afirmação de certa racionalidade e em cuja formulação acusa-se a presença (a que se recusa investimento afetivo) de algo que teria sido da ordem do épico e com que já não se pode o sujeito poético implicar. Em um último retorno a Camões, recorro ainda a Isabel Almeida, para quem a melancolia camoniana estaria dada já nos fundamentos de seu canto, que compatibilizaria engenho e furor ("novo engenho ardente" ou "fúria grande e sonorosa") na constituição de uma vis melancólica "reputada não como o ensimesmamento inerte que Dürer iconograficamente consagrou, mas como promessa de génio - o génio capaz do pathos das grandes lições e decisivas revelações". ${ }^{15}$

A viagem longa ainda possível por artes da razão edifica-se, portanto, destituída do pathos épico ou camoniano. Essa outra melancolia segue acumulando, portanto, ausências, lacunas, escombros. Como nessas estâncias do Canto Primeiro em que sucumbem os deuses, o Destino e a nação:

Os deuses actuam

como se não existissem, e assim

não existem, de facto, com extrema eficácia.

$[\ldots]$

28

Mas o Destino foi (ultimamente) aperfeiçoado Agora o barco e o avião chegam ao chão seguro por força da bússola mecânica, que normalmente

${ }^{15}$ ALMEIDA, 2008, p. 105. 
funciona, ao contrário do Destino

que, por ser invenção antiga,

já vai evidenciando cansaço

e até incompetência.

44

Não falaremos então de um povo

que é demasiado e muito.

Falaremos nesta epopeia apenas de um homem: Bloom.

Bloom abriu os seus dois olhos contraditórios

(um que queria ver o novo, o outro dormir)

dirigindo o olhar para o calmo compartimento onde acabara de entrar.

Bloom, o nosso herói. Eis o que faz primeiro: observa.

Ou nesta passagem do Canto IX, em que se responde à questão "Quem é Bloom?":

88

[...] Quem é Bloom? Ninguém sabe (muito menos ele: está demasiado perto.)

89

É um organismo que tem tudo em potência.

Pode ser um santo, ou vender anjos roubados

à igreja de um padre que salva.

Os homens têm fome, e quando

têm medo fogem e nessa fuga pisam o

chão ou outros animais. $\mathrm{O}$ amor existe, mas não num ser vivo que se move.

$\mathrm{O}$ inesperado insinua-se no que parece definitivo

e ninguém se conhece antes de morrer. Ámen.

90

Confrontam-se pois órgãos genitais, e seus

pequenos afazeres, com discursos

solenes em cima de

montanhas. Religiões loucas expulsam a 
eternidade para um único livro importante que promete salvar o homem até ao seu último átomo.

91

mas Bloom há muito

perdeu o livro essencial;

e das montanhas

mal sabe o nome.

Ou, enfim, o remate do livro, no Canto X:

99

Bloom é um homem.

Teve doenças e deu vários saltos

em que não se conteve para não partir o céu.

Sentiu-se grande e minúsculo,

mas nunca confundiu a dimensão de um dia

com o facto de se cruzar, ou não,

com acontecimentos de grandes proporções.

100

Não procurou proezas extraordinárias, porque viveu o suficiente para perceber as várias epopeias que existem num só dia de Inverno onde o tédio e o frio empurram levemente o homem para a janela. A imobilidade como epopeia ínfima, eis o que descobriu já depois de estar cansado.

Canto X:

149

Procurou o Espírito na viagem à Índia, encontrou a matéria que já conhecia.

Nada agora o faz hesitar; animais bem-comportados e agarrados por coleiras a árvores ladram quando ele passa.

Os sapatos avançam, fuma um cigarro, entra num café e pede um copo de vinho. 
Em um capítulo de Estâncias intitulado "O objeto perdido", ${ }^{16}$ Giorgio Agamben recupera a clássica oposição freudiana entre luto e melancolia, lembrando que, em relação ao luto (em que se acusa uma perda realmente acontecida), a melancolia seria caracterizada por uma circunstância peculiar, já que não haveria clareza em relação ao que se perdeu, não sendo possível, de resto, sequer garantir a ocorrência de uma perda. Ou, ainda, teríamos uma perda objetual que escaparia à consciência. Assim, afirma Agamben, a melancolia constituiria o paradoxo de uma intenção lutuosa que precederia e anteciparia a perda do objeto:

Se a libido nada comporta como se tivesse acontecido uma perda, embora nada tenha sido de fato perdido, isso acontece por que ela encarna uma simulação em cujo âmbito o que não podia ser perdido, porque nunca havia sido possuído, aparece como perdido, e aquilo que não podia ser possuído, porque, talvez, nunca tenha sido real, pode ser apropriado enquanto objeto perdido. Nesta altura, torna-se compreensível a ambição específica do ambíguo projeto melancólico, que a analogia com o mecanismo exemplar do luto havia desfigurado parcialmente e tornado irreconhecível, e que justamente a antiga teoria humoral identificava na vontade de transformar em objeto de abraço o que teria podido ser apenas objeto de contemplação. Cobrindo o seu objeto com os enfeites fúnebres do luto, a melancolia lhes confere a fantasmagórica realidade do perdido; mas enquanto ela é o luto por um objeto inapreensível, a sua estratégia abre espaço à existência do irreal e delimita o cenário em que o eu pode entrar em relação com ele, tentando uma apropriação que posse alguma poderia igualar e perda alguma poderia ameaçar. ${ }^{17}$

A melancolia parece atualizar, então, um espaço epifânico, que permitiria ao sujeito entrar em contato com algo que, de outro modo, não poderia ser captado nem conhecido. Ou, como assinalou Freud, palavras e formas simbólicas permitiriam ao homem "gozar dos próprios fantasmas sem escrúpulo nem vergonha". ${ }^{18}$ Nesse sentido, o

\footnotetext{
${ }^{16}$ AGAMBEN, 2007, p. 43-47.

${ }^{17}$ AGAMBEN, 2007, p. 45.

${ }^{18}$ FREUD apud AGAMBEN, 2007, p. 54.
} 
itinerário melancólico esboçado no título do livro em questão talvez possa ser pensado como o itinerário da forma artística contemporânea: um compromisso indefinidamente reafirmado em relação ao que só se pode denegar. Como formulou Agamben, uma vez que "sua lição consiste em que só se pode apreender o que é inapreensível, o melancólico só se sente bem entre esses ambíguos despojos emblemáticos": ${ }^{19}$ despojos que, contudo, de algum modo capturam "o que só pode ser possuído se estiver perdido para sempre". ${ }^{20}$

\section{Referências}

AGAMBEN, Giorgio. Estâncias: a palavra e o fantasma na cultura ocidental. Tradução de Selvino José Assmann. Belo Horizonte: Editora UFMG, 2007.

ALMEIDA, Isabel. Poesia, furor e loucura: notas sobre Ariosto e Camões. In: Magnum miraculum est homo. José Vitorino de Pina Martins e o humanismo. Lisboa: Faculdade de Letras da UL(Univ. de Lisboa), 2008. p. 94

AMARAL, Fernando Pinto do. Melancolia. In: SILVA, Vítor Manuel de Aguiar e. Dicionário de Luís de Camões. São Paulo: Leya, 2011.

BARRENTO, João. O paradigma da narratividade. In: REIS, Carlos. História Crítica da Literatura Portuguesa: do neo-realismo ao pósmodernismo. São Paulo: Verbo (Brasil), 2005.

BERARDINELLI, Cleonice. Os excursos do Poeta n'Os Lusíadas. In: . Estudos Camonianos. Rio de Janeiro: Nova Fronteira/Cátedra Padre António Vieira/Instituto Camões, 2000. p. 31-55.

CAMÕES, Luís de. Obra completa. Rio de Janeiro: Nova Aguilar, 1988. (Biblioteca Luso-Brasileira, Série Portuguesa).

COELHO, Eduardo Prado. Dez anos de poesia portuguesa: o retorno à imagem e à narrativa. In: GOMES, Renato Cordeiro e MARGATO, Izabel. Literatura/ Política/ Cultura (1994-2004). Belo Horizonte: Editora UFMG, 2005.

CUNHA, Maria Helena R. e PIVA, Luiz. Lirismo e Epopéia em Luís de Camões. São Paulo: Cultrix/EDUSP, 1980.

\footnotetext{
${ }^{19}$ AGAMBEN, 2007, p. 55.

${ }^{20}$ AGAMBEN, 2007, p. 56.
} 
FRANÇA NETO, Osvaldo. A Bejahung nas conexões da psicanálise. Psicologia Clínica, Rio de Janeiro, v. 18, n. 1, p. 153-163, 2006. p. 153. FREUD, Sigmund apud AGAMBEN, Giorgio. Estâncias: a palavra e o fantasma na cultura ocidental. Tradução de Selvino José Assmann. Belo Horizonte: Editora UFMG, 2007. p. 54.

LAUSBERG, Heinrich. Elementos de Retórica Literária. Lisboa: Calouste Gulbenkian, 1965.

MOURA, Vasco Graça. Recensão crítica a Uma viagem à Índia, de Gonçalo M. Tavares. Colóquio/Letras. Recensões Críticas, n. 177, maio 2011, p. 271-274.

NASCIMENTO, João C. do. Poemas narrativos portugueses. Lisboa: Minerva, 1949.

NEIVA, Saulo (Org.). Désirs \& débris d'épopée au XXe siècle. Berna: Peter Lang, 2008.

NEIVA, Saulo. Avatares da epopeia na poesia brasileira do final do século XX. Recife: Massangana, 2009.

OLIVEIRA, Nelson de. Axis Mundi: o jogo de forças na lírica portuguesa contemporânea. São Paulo: Ateliê, 2009.

PAZ, Octavio. Cantar e contar (sobre o poema extenso). In: voz. Tradução de Waldir Dupont. São Paulo: Siciliano, 1993. . A outra

SILVA, Vítor Manuel de Aguiar e. Camões: Labirintos e Fascínios. Lisboa: Cotovia, 1994.

TAVARES, Gonçalo M. Uma viagem à Índia: melancolia contemporânea (um itinerário). São Paulo: Leya, 2010. 
